\title{
Multidecadal Drought Cycles in the Great Basin Recorded by the Great Salt Lake: Modulation from a Transition-Phase Teleconnection
}

\author{
SHIH-Yu WANG AND RobeRT R. GILLIES \\ Utah Climate Center, and Department of Plants, Soils, and Climate, Utah State University, Logan, Utah \\ THOMAS REICHLER \\ Department of Atmospheric Sciences, University of Utah, Salt Lake City, Utah
}

(Manuscript received 24 November 2010, in final form 28 July 2011)

\begin{abstract}
This study investigates the meteorological conditions associated with multidecadal drought cycles as revealed by lake level fluctuation of the Great Salt Lake (GSL). The analysis combined instrumental, proxy, and simulation datasets, including the Twentieth Century Reanalysis version 2, the North American Drought Atlas, and a 2000-yr control simulation of the GFDL Coupled Model, version 2.1 (CM2.1). Statistical evidence from the spectral coherence analysis points to a phase shift amounting to 6-9 yr between the wet-dry cycles in the Great Basin and the warm-cool phases of the interdecadal Pacific oscillation (IPO). Diagnoses of the sea surface temperature and atmospheric circulation anomalies attribute such a phase shift to a distinctive teleconnection wave train that develops during the transition points between the IPO's warm and cool phases. This teleconnection wave train forms recurrent circulation anomalies centered over the southeastern Gulf of Alaska; this directs moisture flux across the Great Basin and subsequently drives wet-dry conditions over the Great Basin and the GSL watershed. The IPO life cycle therefore modulates local droughts-pluvials in a quarter-phase manner.
\end{abstract}

\section{Introduction}

The Great Salt Lake (GSL) is a large closed-basin lake located in the heart of the American West. As a pluvial lake, the GSL integrates hydrological forcings over a substantial watershed that, when coupled with the lake's shallowness, results in extensive fluctuations in elevation (Fig. 1a; blue shaded graph). The large drainage area that constitutes the GSL tends to dampen out the interannual variability and so has a tendency to be more responsive to climatic variabilities at longer time scales (Lall and Mann 1995; Mann et al. 1995). As a result, the tendency of the GSL elevation (denoted as $\Delta$ GSL) reflects the recurrent wet-dry periods that have characterized the American West (Cook et al. 2007), since any abrupt and prolonged downtrends (uptrends) of the GSL elevation are usually reflective of drought (pluvial)

Corresponding author address: S.-Y. Simon Wang, Utah Climate Center, Utah State University, 4825 Old Main Hill, Logan, UT 84322-4825.

E-mail: simon.wang@usu.edu conditions in the Great Basin ${ }^{1}$ [Utah Division of Natural Resources (UDNR; UDNR 2007]. A wealth of research (Gray et al. 2003; Seager et al. 2005; Herweijer et al. 2007; references therein) has established a link between lowfrequency climate variability in the American West and sea surface temperature (SST) in the tropical Pacific. A strong relationship has also been found between variabilities of the GSL elevation and the Pacific climate (e.g., Mann et al. 1995; Moon and Lall 1996). Recent studies (Wang et al. 2010; Gillies et al. 2011) have noticed two distinct frequency bands in the power spectrum of the $\Delta$ GSL that are highly responsive to the evolution of decadal-scale oscillatory modes in the tropical Pacific; these two frequency bands are reflected in Fig. 1b-spectrum of the annual $\Delta \mathrm{GSL}$ - with one at the quasi-decadal time scale (10-15 yr) and the other at the multidecadal time scale $(\sim 30 \mathrm{yr})$.

Focused research on the quasi-decadal time scale by Wang et al. $(2010,2011)$ found that the hydrological

\footnotetext{
${ }^{1}$ The Great Basin referred to here includes the GSL watershed.
} 
(a)

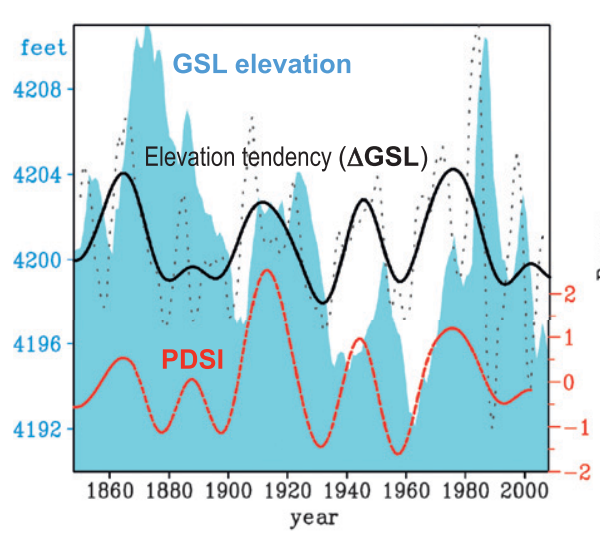

(b) $\triangle \mathrm{GSL}$ spectrum

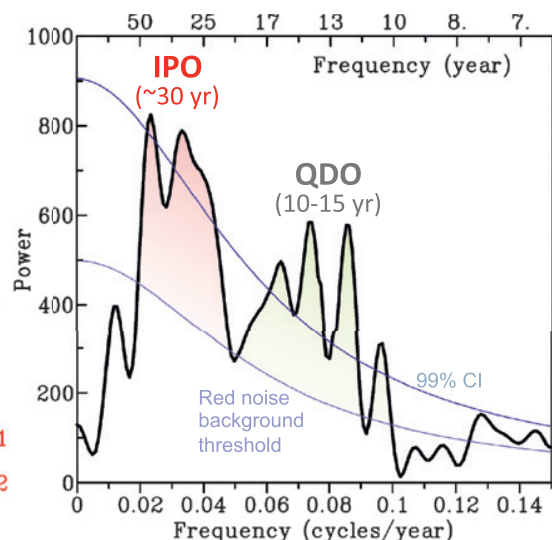

FIG. 1. (a) Lake elevation of the GSL (blue shaded graph) superimposed with the elevation tendency ( $\triangle$ GSL; black solid line) and the PDSI (red dashed line) averaged from the nearby four grid points as outlined in Fig. 2a, after a 20-yr low-pass filter. The unfiltered $\Delta$ GSL is shown with a gray dotted line for reference. (b) MTM spectral analysis of the $\Delta$ GSL during the period 1848-2008 with $2 \pi$ taper, superimposed with the $99 \%$ confidence interval (CI; upper blue line) and the red noise background threshold (lower blue line).

factors controlling the $\Delta \mathrm{GSL}$ respond to a particular teleconnection that is induced at the transition point of the Pacific quasi-decadal oscillation (QDO) - the transition that lies approximately half-way between the warmest and coldest SST anomalies in the tropical central Pacific. Such circumstance in process creates consistent time lags (on the order of $6 \mathrm{yr}$ ) between the Pacific QDO and the GSL elevation and subsequently results in a highly coherent yet opposite correspondence between the two. Applying this concept, Gillies et al. (2011) developed a statistical model to forecast the annual GSL elevation out to 8 yr. Nevertheless, the model in Gillies et al. exhibits a wet bias that persists for two decades followed by a dry bias in another two decades. Such biases apparently are linked to multidecadal variability that is not as well understood. Correcting this bias requires improved knowledge of the multidecadal variations of the GSL elevation, drought cycles, and associated teleconnections.

Expanding upon the recent work of Wang et al. (2010) and Gillies et al. (2011), the purpose of this paper is to document the covariability and processes of multidecadal climate modes in both the Pacific and the Great Basin, with an emphasis on the impact over the GSL watershed. The analysis utilized recent climate datasets that span at least a century; these datasets are introduced in section 2. The covariability of the GSL elevation with drought and SST anomalies was examined and is presented in section 3. Circulation and SST patterns associated with variations in the GSL elevation, as well as results of the CM2.1 simulation, are discussed section 4 . A summary with some conclusions is provided in section 5 .

\section{Data sources}

Various sets of century-long gridded data were utilized to facilitate our line of analysis, including the Twentieth Century Reanalysis (20CR) version 2 that assimilated both sea level pressure and SST observations at a $2^{\circ} \times 2^{\circ}$ resolution (Compo et al. 2011), the North American Drought Atlas providing the tree-ring-reconstructed Palmer Drought Severity Index (PDSI) at a $2.5^{\circ} \times 2.5^{\circ}$ resolution and has been low-pass filtered with $20 \mathrm{yr}$ (Cook and Krusic 2004), and the National Oceanic and Atmospheric Administration (NOAA) Extended Reconstruction SST (ERSST) version 3 at a $2^{\circ} \times 2^{\circ}$ resolution (Smith et al. 2008). The 20CR data, with a time span of 1871-present, was especially insightful to the study of multidecadal climate variations because it enabled the empirical analysis of atmospheric circulations beyond the 60 -yr operational life span of upper-air sounding records. To verify the SST variability prior to World War II, we adopted a longterm Niño-3.4 SST record that was constructed by Bunge and Clarke (2009) from ship-borne SST observations calibrated with the coral $\delta^{18} \mathrm{O}$ record for the period 1873 2008. We also utilized a 700-yr (1300-2003) record of the Niño-3.4 index that was constructed from tree rings collected in Mexico and western Texas by Cook et al. (2009), denoted as CNiño-3.4. In addition to these observation-based datasets, we examined a 2000 -yr-long preindustrial control simulation performed using the Geophysical Fluid Dynamics Laboratory (GFDL) Coupled Model, version 2.1 (CM2.1), as documented in Delworth et al. (2006) and Wittenberg (2009). As is described in Wittenberg (2009), the simulation was integrated 
for $2000 \mathrm{yr}$ with estimates of solar irradiance, land cover, and atmospheric composition fixed in 1860.

\section{Covariability between the GSL elevation, drought, and Pacific climate}

The annual $\Delta$ GSL during the 1848-2008 period is shown in Fig. 1a (accumulated for the calendar year), overlaid with the PDSI averaged from the nearest four grid points surrounding the GSL. The $\Delta$ GSL was smoothed using a 20 -yr low-pass filter with a minimum slope constraint (Mann 2004) in order to be consistent with the low-passed PDSI that comes with the North American Drought Atlas. As shown in Fig. 1a, both the $\Delta$ GSL and the PDSI reveal marked multidecadal variability and are coherent with each other. This is not surprising because it reflects the fact that changes in the GSL elevation respond to the wet and dry periods of the surrounding region. The result nevertheless concurs and validates the tree-ring-reconstructed PDSI records for this region. To focus on the multidecadal spectral peaks as shown in Fig. 1b, hereinafter all time series and regression analyses use 20-50-yr bandpass-filtered data. The filtering was performed using the Hamming-Windowed filter developed specifically for short-length time series while conserving the two ends (Iacobucci and Noullez 2005).

The association between the bandpassed $\Delta \mathrm{GSL}$ and PDSI is shown in Fig. 2a by the one-point correlation map, revealing a significant $(p<0.05)^{2}$ response surrounding the Great Basin and the Upper Colorado River basin. A drought pattern like this is distinct from those affecting the southwestern United States associated with prevailing La Niña conditions (e.g., Schubert et al. 2004; Seager et al. 2005; Herweijer et al. 2007). Correspondingly, the correlations between the bandpassed $\triangle$ GSL and annualmean SST anomalies (Fig. 2b) are insignificant in the central-eastern tropical Pacific (i.e., the Niño-3.4 region) and elsewhere, except the area in the western tropical Pacific between Indonesia and Australia that shows significant correlations. The overall SST pattern lacks a tropical Pacific forcing and is a departure from the El Niño-Southern Oscillation (ENSO) pattern. This suggests that the $\Delta$ GSL and drought conditions in the Great Basin do not respond to the multidecadal variability of ENSO, at least not directly. We plotted in Fig. $2 \mathrm{c}$ the bandpassed Niño-3.4 index of Bunge and Clarke (2009) and the bandpassed PDSI of the Great Basin to further explore the multidecadal spectral band

\footnotetext{
2 The significance test has taken into account the reduced degree of freedom (DoF) due to filtering. In this case the DoF was reduced to 7 from 157 given the 20 -yr cutoff frequency.
}

(a) Correlation map: $\triangle G S L$ vs. PDSI 1848-2005

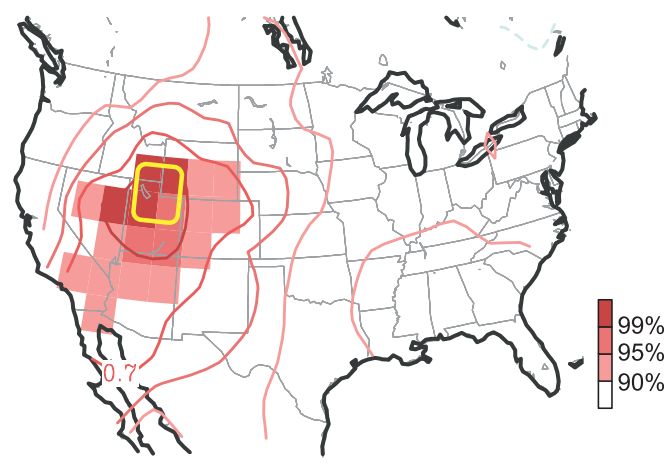

(b) Correlation map: $\triangle G S L$ vs. SST
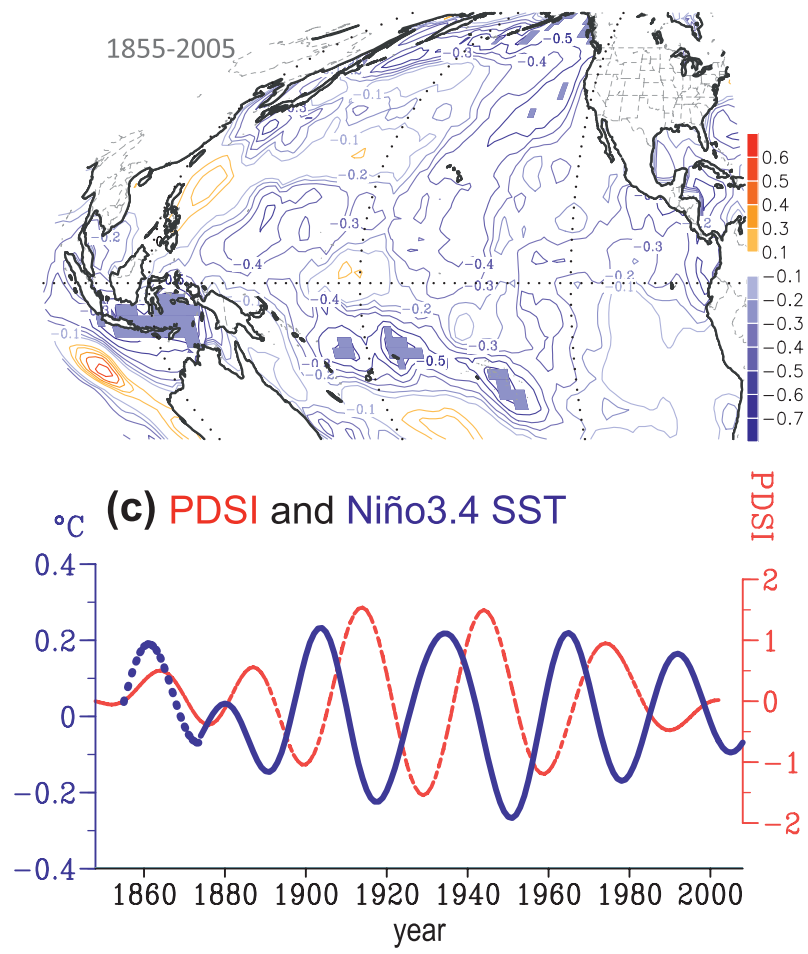

FIG. 2. Correlation maps between the $\Delta$ GSL and the (a) PDSI and (b) ERSST. All data were annual means bandpassed for 20 $50 \mathrm{yr}$. Values that are significant at the $95 \%$ confidence interval are shaded. The four grid points used for the PDSI in Fig. 1a are outlined by a yellow box in (a). (c) Time series of the 20-50-yr bandpassed PDSI (red dashed line) and Niño-3.4 SST anomalies (blue line) constructed by Bunge and Clarke (2009); dotted line before 1873 was derived from the ERSST data.

of the $\Delta \mathrm{GSL}$. The multidecadal variations of the two time series are not coherent; instead, they exhibit a phase shift with the Niño-3.4 index consistently leading the PDSI on the order of 6-9 yr.

To obtain a statistical description of these observed features, the covariability between the SST, droughts, and the $\Delta$ GSL was examined through the multitaper 


\section{PDSI vs. $\triangle G S L$}

(a) Amplitude and phase

(b) Frequency (year)

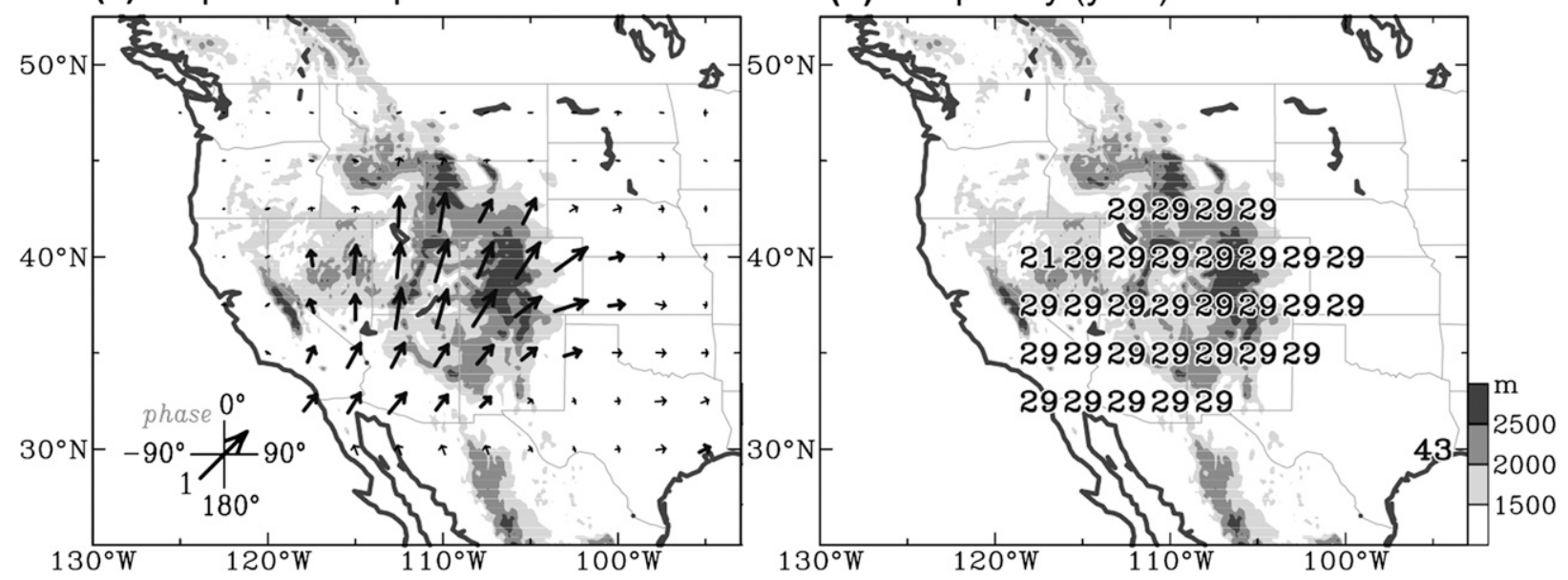

ERSST vs. $\triangle G S L$

(c) Amplitude and phase

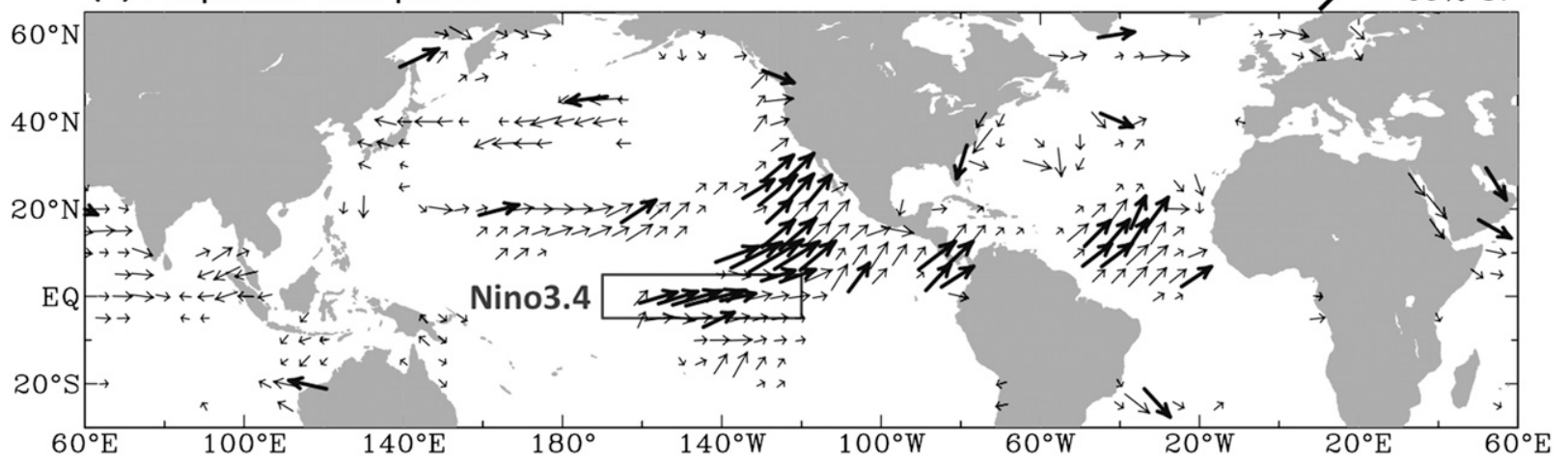

FIG. 3. Maximum coherence amplitudes (vector length) and corresponding phases (vector direction) between the $\Delta$ GSL and the (a) PDSI and (c) ERSST within the multidecadal frequency band. (b) Significant frequencies corresponding to (a). Coherence amplitudes above the $95 \%$ confidence interval (CI) are shown in red. In (c) coherence amplitudes above the $90 \%$ CI (but below $95 \%$ ) are shown in black.

method (MTM) of spectral coherence analysis based on Mann and Park (1996). Our analysis proceeds along the following lines: first, the MTM spectral coherence was computed between the (unfiltered) annual $\triangle$ GSL and the PDSI so that the spatial distribution of their coherence amplitude and phase could be constructed at each grid point. Since our focus was on the multidecadal time scale, only the maximum amplitude within the $20-50$-yr frequency band and its corresponding phase-averaged among the significant amplitudes-are displayed. The coherence amplitude is presented as the vector length and the phase difference is presented as the vector direction. This approach, which follows that used in Wang et al. (2010, their Fig. 5), has a similar purpose as the MTM singular value decomposition (e.g., Mann and Park 1993), but is different in that we were interested in the identification of a spectral bandwidth, rather than specific spectral peak(s) of variability.

Figure $3 \mathrm{a}$ shows that the coherence amplitudes at or above the $90 \%$ confidence interval appear in the Great Basin with simultaneous phases $\left(0^{\circ}\right)$ and in the eastern Rocky Mountains and the southwest with shifted phases $\left(45^{\circ}-90^{\circ}\right)$. Such phase shifts suggest that the PDSI in those regions leads the $\Delta$ GSL by about $6-9 \mathrm{yr}$. This $0^{\circ}$ phase of spectral coherence surrounding the GSL is not surprising, but rather is a "sanity check" for the two independent, yet physically related datasets. The corresponding frequencies of the significant amplitudes are uniformly $29 \mathrm{yr}$ over the Intermountain West (Fig. 3b), consistent with the peak $\Delta$ GSL spectrum in Fig. $1 b$. 


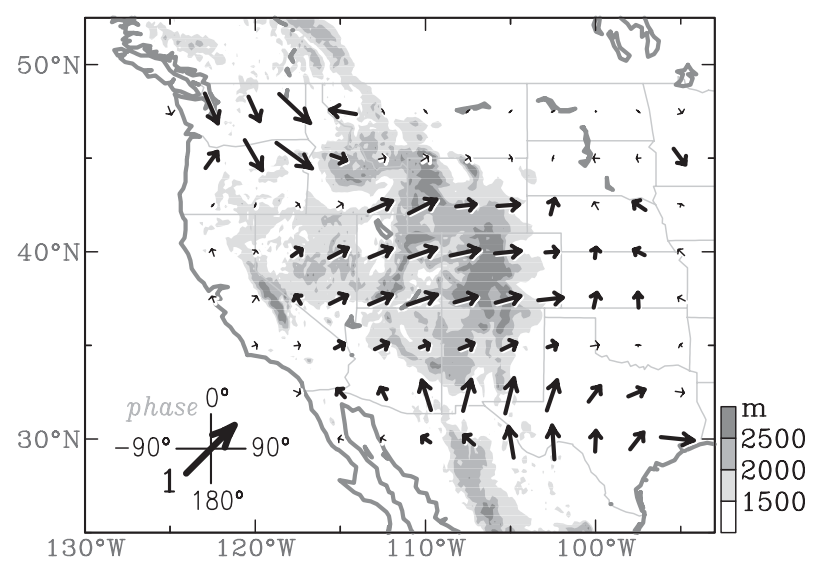

FIG. 4. As in Fig. 3a, but for coherence amplitudes between the CNiño-3.4 index and the PDSI during the $704 \mathrm{yr}$ of 1300-2003.

Next in line was the spectral-coherence analysis implemented between the annual $\Delta$ GSL and annual SST anomalies, as shown in Fig. 3c. Immediately apparent is that significant (maximum) amplitudes within the multidecadal frequency cover an area encompassing the Niño-3.4 region at $90^{\circ}$, as well as the subtropical eastern Pacific and part of the tropical North Atlantic at $45^{\circ}$. The significant frequencies of spectral coherence amplitudes range between 28 and $32 \mathrm{yr}$ over these regions (not shown). The result thus supports the phase shifts as was observed between the PDSI and the Niño-3.4 index (cf. Fig. 2c). Throughout the Pacific basin, the distribution of the spectral coherence seems coincident with SST pattern associated with the ENSO-like decadal variability (Zhang et al. 1997), which is characterized by stronger tropical loading compared to the Pacific decadal oscillation, which is confined to the north of $20^{\circ} \mathrm{N}$ (Mantua et al. 1997). Because of this, in the discussion that follows we adopt the term interdecadal Pacific oscillation (IPO) to depict this basin-scale interdecadal variability, following that defined in Folland et al. (2002). ${ }^{3}$

Based on the results in Figs. 2 and 3, it is reasonable to use the multidecadal SST variation in the Niño-3.4 region as an indicator that pertains to the IPO. However, given the relatively short instrumental records it was not possible to satisfactorily address the significance of multidecadal variability. To extend the analysis, we utilized the 700-yr CNiño-3.4 index. Following Fig. 3, the spectral coherence between the CNiño-3.4 index and the treering PDSI (1300-2003) is shown in Fig. 4. Significant amplitudes are in phase over western Texas and southern New Mexico and are nearly out of phase in the Pacific

\footnotetext{
${ }^{3}$ The terms "interdecadal" and "multidecadal" are used interchangeably in the text.
}

Northwest; these essentially sandwich the $90^{\circ}$ phase differences over the Great Basin. While the in-phase (outof-phase) response in the Southwest (Northwest) reflects the well-known IPO influence on precipitation and drought (e.g., Gershunov and Barnett 1998; Herweijer et al. 2007), the $90^{\circ}$ phase differences in the Great Basin and the Upper Colorado River basin suggest a "delay" of drought response to the IPO's extreme (warm/cold) phases, similar to that revealed in Fig. 2c. Analysis using the instrumental data of ERSST and of Bunge and Clarke (2009) (not shown) obtained a consistent result with phase difference oriented exactly at $90^{\circ}$ over the Great Basin. These separate lines of investigation lend further credence to the quarter-phase shift between the $\triangle$ GSL and the IPO as was evident in Fig. 3c.

\section{Dynamical linkages}

\section{a. SST and circulation covariability}

To substantiate the implication of the spectral coherence analysis, the 20CR data and observed SST were analyzed. However we used the bandpassed CNiño-3.4 index to represent the IPO because of its long record and, as will be shown, its reasonable depiction of the IPO pattern. The circulation and SST patterns in association with the IPO life cycle were constructed through lagged regressions, with a $3-\mathrm{yr}$ interval beginning year $0(\mathrm{yr}+0)$ through year $9(\mathrm{yr}+9)$. All variables were annual means bandpass filtered with 20-50 yr. As shown in Fig. 5, the simultaneous response of the SST anomalies to the CNiño-3.4 (yr+0) depicts the classic IPO pattern consisting of widespread eastern tropical warming surrounded by midlatitude cooling the so-called horseshoe pattern (e.g., Zhang and Delworth 2007). The regression coefficients near the Niño-3.4 region are significant $(p<0.01)$, even though the degrees of freedom have been drastically reduced because of filtering (Livezey and Chen 1983). Such a significant response serves to validate the tree-ring-reconstructed CNiño-3.4 index in terms of the IPO signal. Comparing Fig. $5(\mathrm{yr}+0)$ with Fig. $3 \mathrm{c}$, the distribution of significant coherence amplitudes between the $\Delta$ GSL and SSTs is coincident with the IPO pattern, particularly in the tropical Pacific. Beginning yr +3 the tropical Pacific warming gradually dissipates, with cooling developing in the northeastern Pacific. This is followed by the gradual emergence of the cool phase IPO structure after $\mathrm{yr}+12$ (not shown). Such a SST evolution at the interdecadal time scale is consistent with that illustrated in Allan (2000) and subsequent studies. In particular, the westward progression of tropical warming and the eastward extension of midlatitude cooling possibly result from a slow clockwise rotation of the Pacific subtropical gyre as was proposed 


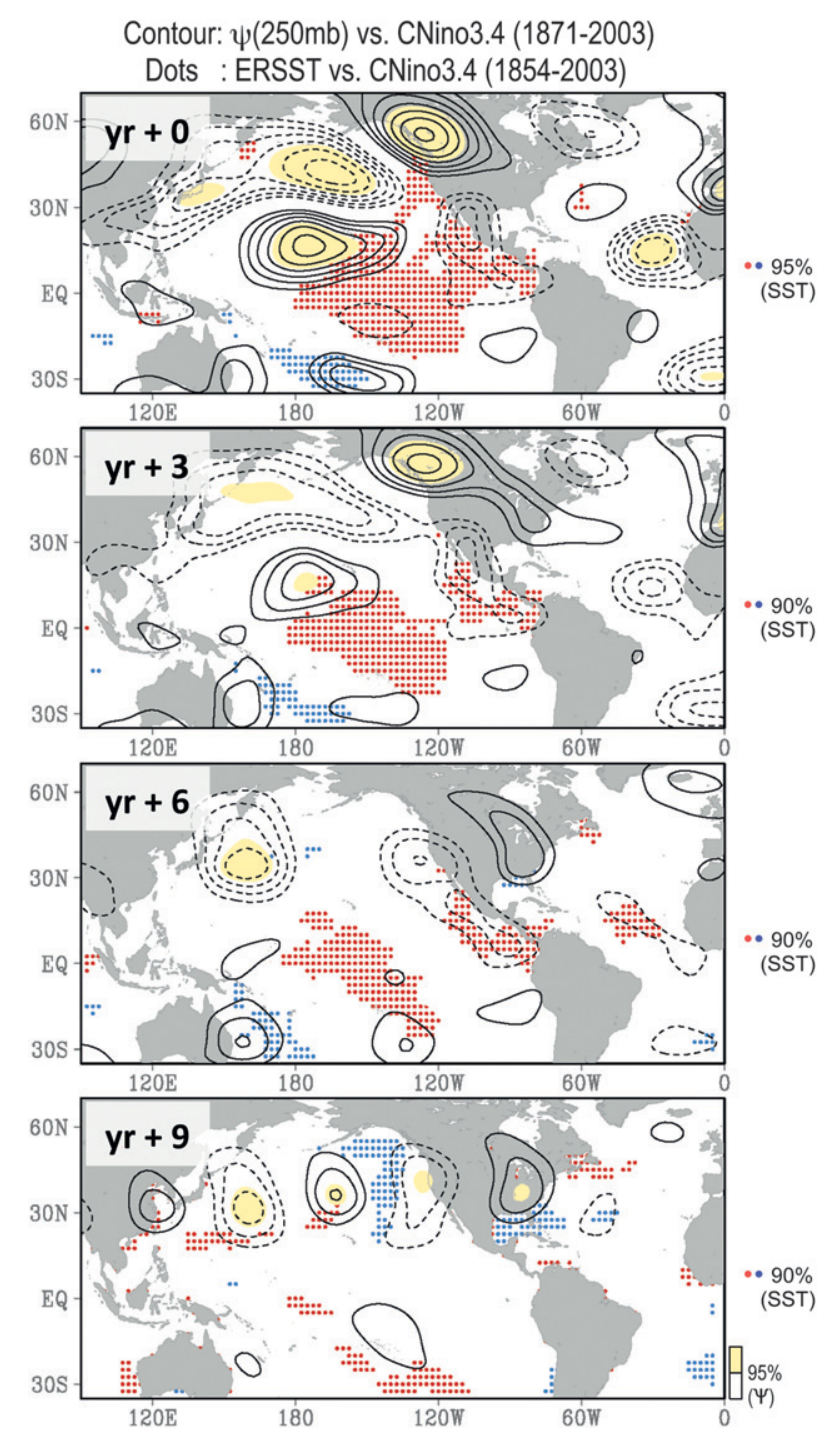

FIG. 5. (a) Patterns of the 250-mb streamfunction $\psi$ (contours) and SSTs (dotted) regressed upon the CNiño-3.4 index at different lags. The contour interval is $10^{-6} \mathrm{~m}^{2} \mathrm{~s}^{-1}$, omitting zeros. All data were bandpass filtered for 20-50 yr. Values at the $95 \%$ confidence interval are indicated by yellow shadings for $\psi$ and by dots for the SSTs, based on the Student's $t$ test.

by Zhang and Levitus (1997). At yr +9 , the basin-wide SST pattern bears some resemblance with Fig. 2b showing weak anomalies in the Niño-3.4 region and substantial cooling in the northeastern Pacific. These results agree with the inference made from Fig. $3 c$ that the $\triangle \mathrm{GSL}$ (and local drought) is linked to the IPO's transition point between the warm and cool phases, rather than its extreme phases.

A regression between the CNiño-3.4 index and the 250-mb streamfunction allows one to construct the circulation pattern associated with the IPO evolution, which is overlaid in Fig. 5. For the streamfunction we used the cold season mean (November-April) because of the rainy-snow season of this region (regression of the annual mean (not shown) obtained a consistent pattern with weaker magnitudes.) At $\mathrm{yr}+0$, a classic Pacific-North American (PNA) pattern (Horel and Wallace 1981) emerges in response to the widespread tropical Pacific warming. During $\mathrm{yr}+6$ through $\mathrm{yr}+9$, the circulation transforms into a weaker, zonally oriented short-wave train across the midlatitudes. Beginning $\mathrm{yr}+6$, a cyclonic cell develops over western North America and this is known to modulate precipitation in the GSL watershed (Wang et al. 2010). Such covarying circulation and SST features echo the finding of Wang et al. (2011) that the lack of dominant tropical Pacific SST forcing significantly reduces the magnitude of longer-wave circulation anomalies (like the PNA) while at the same time promoting the emergence of shorter-wave responses. The short-wave train is possibly a Rossby wave response to upstream forcings, such as warm SST anomalies in the western North Pacific ( $\mathrm{yr}+9)$. A forcing source such as this is plausible as was found in earlier studies (Branstator 1983; DeWeaver and Nigam 2004; Wang et al. 2011) and will be discussed further later.

On the regional perspective, we examined the column water vapor flux $\mathbf{Q} \equiv \int_{p_{S}}^{300 \mathrm{mb}}(q \mathbf{V}) d p$ derived from the 20CR data (where $q$ is specific humidity, $\mathbf{V}$ is wind, and $p$ is pressure) and regressed upon the CNiño-3.4 index. The results were overlaid with corresponding patterns of the PDSI regressions (1300-2003) as shown in Fig. 6. During the warm-phase IPO ( $\mathrm{yr}+0)$, a cyclonic cell of water vapor flux develops in the eastern North Pacific reflecting the eastward-shifted Aleutian low and its influence over the American West. The southwesterly flux, associated with this cyclonic cell apparently contributes to the positive PDSI (i.e., wet conditions) in the southwest, while the easterly flux contributes to the negative PDSI (i.e., dry conditions) in the northwest. From $\mathrm{yr}+6$ through $\mathrm{yr}+9$, the cyclonic cell shifts northeastward, following the northward migration of cyclonic $\mathbf{Q}$, while enabling southwesterly moisture transport into the Great Basin. At yr +9 the Great Basin is characterized by wet conditions in response to this anomalous circulation. Noteworthy is that the PDSI and SST patterns at $\mathrm{yr}+9$ echo the Saskatchewan type of precipitation anomalies in western Canada that are associated with a vastly different SST pattern from that of the IPO (Cayan et al. 1998). Even though the regression pattern of $\mathbf{Q}$ is largely insignificant, because of filtering, the patterns of $\mathbf{Q}$ and PDSI appear to correspond to each other. During the cool-to-warm IPO transitions (not shown), a reversed situation is formed leading to drought in the southwest and its subsequent occurrence in the Great Basin. 
Vector: Q \& CNino3.4 (1871-2003) Shading: PDSI \& CNino3.4 (1300-2003)
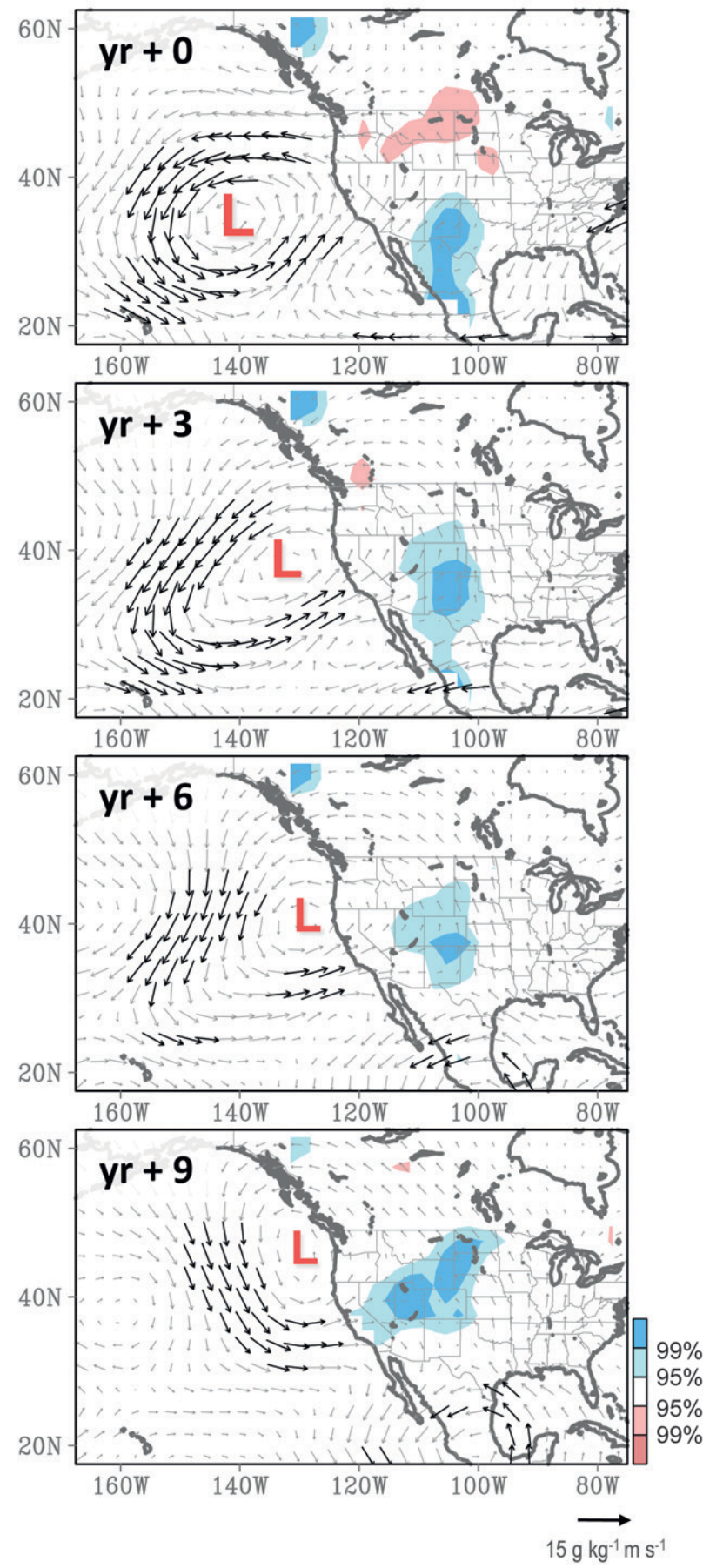

FIG. 6. Patterns of the column-integrated water vapor flux $\mathbf{Q}$ (vectors) and the PDSI (shadings) regressed upon the CNiño-3.4 index at different lags. All data were bandpass filtered for 25-50 yr. Values at the $95 \%$ confidence interval are indicated by thick black vectors for $\mathbf{Q}$ and by shadings for the PDSI, based on the Student's $t$ test.

\section{b. Circulation maintenance}

Regression analysis with smoothed data does, however, raise concern with regard to spurious correspondence. To verify the regression pattern, we performed a composite analysis using unfiltered data. Based upon the IPO evolution defined by the multidecadal Niño-3.4 index in Fig. 2c, we selected five warm-to-cool transition periods (1883-87, 1906-10, 1942-46, 1968-72, and 1999-2003) and five cool-to-warm transition periods (1875-79, 189599, 1920-24, 1953-57, and 1984-88), each period comprising $5 \mathrm{yr}$. Given the cold-season precipitation maxima in the region, the analysis focused on the November-April period with the year centered in January. Figure 7a shows the differences of the composite streamfunction at $250 \mathrm{mb}$ between the warm-to-cool and cool-to-warm phases, superimposed with the significance level of $95 \%$ per Student's $t$ test. A zonally oriented short-wave train is clearly visible, while its cyclonic cell over the Gulf of Alaska suggests that the jet stream and storm track are enhanced over the Great Basin (cf. Fig. 10 of Wang et al. 2010). In addition, it is worth mentioning that the composite shortwave train corresponds with the regression pattern at $\mathrm{yr}+9$ (Fig. 5); this is further supported by a significant spatial correlation coefficient of 0.67 between the composite and regression patterns within the domain of Fig. 7.

The differences of composite SST (Fig. 7b, shadings) reveal weak anomalies in the tropical and subtropical Pacific. Nonetheless, the SST pattern also bears some resemblance with Fig. 5 at $y r+9$. Apparently the shortwave train formed during the IPO transitions is not directly excited from ENSO-like, tropical Pacific forcings. To explore its forcing source, we computed the waveactivity flux - a measure of the phase-independent wave activity for stationary and migratory waves. Based upon the Eliassen-Palm relation for stationary wave activity (Plumb 1985), Takaya and Nakamura (2001) formulated the wave-activity flux $\mathbf{W}$ as

$\mathbf{W}=\frac{1}{2|\mathbf{V}|}\left[\begin{array}{l}u\left(\psi_{x}^{2}-\psi \psi_{x x}\right)+v\left(\psi_{x} \psi_{y}-\psi \psi_{x y}\right) \\ u\left(\psi_{x} \psi_{y}-\psi \psi_{x y}\right)+v\left(\psi_{y}^{2}-\psi \psi_{y y}\right)\end{array}\right]$,

where $\psi$ is the perturbation streamfunction, the subscripts represent partial derivatives, and $\mathbf{V}$ is the mean horizontal winds $(u, v)$. The presentation of Eq. (1) follows that in Jiang and Lau (2008). The vector $\mathbf{W}$ is suited for Rossby wave packets associated with anomalous circulations propagating through the time-mean flow. The calculation of Eq. (1) is independent of any spatial or time averaging, making it ideal for analyzing wave activity over different time scales.

As shown in Fig. 7b, the flux of stationary wave activity propagates mainly along the short-wave train around 


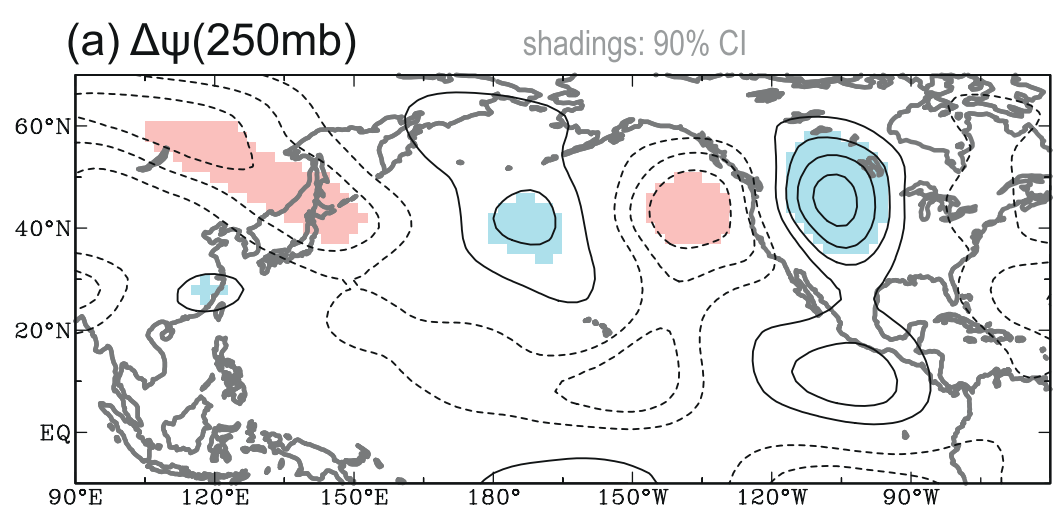

(b) $\triangle$ SST (shadings), wave flux (vectors)

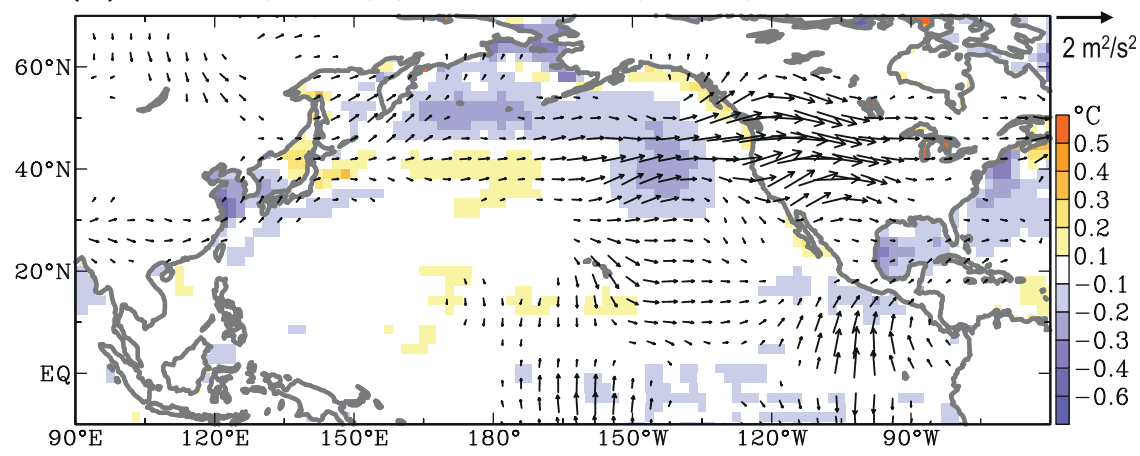

FIG. 7. (a) Differences of the composite, unfiltered 250-mb streamfunction between the warm-to-cool and the cool-to-warm transition phases of the IPO as defined by the Niño-3.4 index in Fig. 2c. Shadings indicate areas that are significant at the $90 \%$ confidence interval (CI) per the Student's $t$ test. (b) The composite differences of significant SST anomalies (shadings at the $90 \% \mathrm{CI}$ ) as well as the wave-activity fluxes. All variables were detrended before the composite.

$40^{\circ} \mathrm{N}$, from the western North Pacific toward North America. Areas of divergent flux in the central North Pacific and near Japan suggest a possible Rossby wave source region there. Meanwhile, the divergent flux over the U.S. West Coast indicates a regeneration of wave energy which, in turn, propagates into North America. On the other hand, there is no apparent energy source in the tropical central-western Pacific and this corresponds to the weak tropical SST anomalies. There is, however, a region of poleward wave-activity flux emanating from the tropical eastern Pacific, though the flux does not reach North America. The diagnosis points to primary midlatitude forcing in maintaining the transition-phase teleconnection of the IPO.

\section{c. CM2.1 simulation}

The relatively short length of observational data presents a constant challenge to the study of multidecadal variability. In seeking an alternative, yet dependable measure of multidecadal variability, we analyzed the 2000-yr-long control simulation from CM2.1. Numerous studies have established that, among the models that contributed to the Third Coupled Model Intercomparison Project (CMIP3) database, CM2.1 has a realistic mean climate (Reichler and Kim 2008), ENSO variability (van Oldenborgh et al. 2005), and SST variability over the region of the IPO (Santer et al. 2009). In addition, Pierce et al. (2009) have demonstrated that CM2.1 simulates reasonably the influences of ENSO and IPO on western U.S. precipitation.

The baseline performance of this simulation was examined through a standard empirical orthogonal function (EOF) analysis of annual SST within the global domain as outlined in Fig. 3c, but was confined to south of $50^{\circ} \mathrm{N}$ to avoid the known bias of simulated sea ice. The first EOF (not shown) reveals a striking ENSO pattern that is consistent with previous studies (e.g., Wittenberg et al. 2006). Applying the MTM spectral analysis on this principal component (PC1; Fig. 8a), significant spectral peaks appear between 20 and $50 \mathrm{yr}$. Using this bandwidth, we then computed the EOF of the bandpass-filtered SST of CM2.1 to depict the simulated IPO. The first leading mode (Fig. 8b) reveals a basin-scale SST variation pattern similar to that of the observed IPO, despite a subtropical discontinuity near $15^{\circ} \mathrm{N}$ between the equatorial warm tongue and the midlatitude warm anomalies. To examine the representation of model Niño-3.4 index on model IPO, 


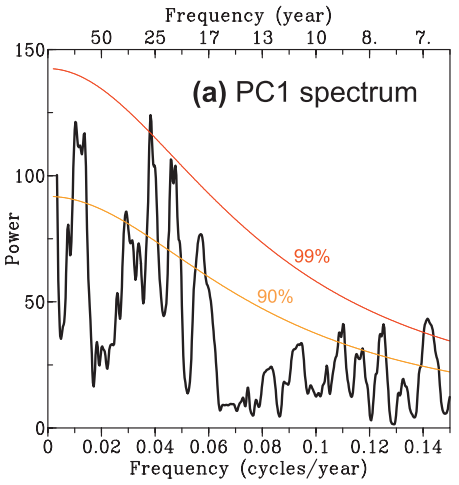

(b) EOF1 (39\%)

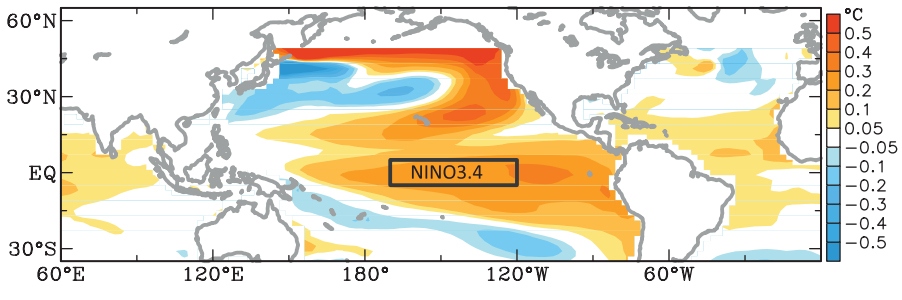

GFDL CM2.1 2000 years

FIG. 8. The 2000-yr CM2.1 simulation analyzed with (a) MTM spectrum of the first principal component (PC1) of unfiltered annual SSTs where the color lines indicate the $95 \%$ and $99 \%$ significance levels, and (b) first EOF of the 20-50-yr bandpassed SST.

we correlated the bandpassed SSTs with the bandpassed Niño-3.4 index. The correlation pattern (not shown) resembles that in Fig. 8b, suggesting a strong covariability between the simulated Niño-3.4 index and IPO. This result is in agreement with previous findings (e.g., Schubert et al. 2009) that CM2.1 is one of the few coupled models that can capture the Pacific decadal variability and associated teleconnection impacts in North America.

Next, the MTM coherence analysis was performed for the annual precipitation and Niño-3.4 index (Fig. 9a). Note that, model precipitation was used as a proxy for the PDSI because of insufficient variables that are required to compute the PDSI. Nonetheless, within the multidecadal frequency band, significant coherence amplitudes are distributed to the west of the Rockies. Compared with the observations in Fig. 4, the simulated precipitation response to the IPO appears to shift westward and shows weak variability over the Rocky Mountains. Regardless of biases like these, an area of $90^{\circ}$ phase covers northern California and the Great Basin and is sandwiched between some $0^{\circ}$ phase region in the south and some $180^{\circ}$ phase in the north, consistent with the observation. The significant frequencies of coherence amplitudes over this region range between 28 and $32 \mathrm{yr}$ (not shown), which is close to the 29 -yr frequencies as observed in Fig. 3b. This pattern of precipitation responses to the IPO, albeit spatially shifted from that of the observations, presents complementary evidence to the transition-phase teleconnection associated with the IPO and its climate impact over the Great Basin.

\section{Summary and conclusions}

Utilizing available century-long datasets, longer-term proxy climate records, and a $2000-y r$ simulation of the CM2.1 model, this study revealed evidence of consistent modulation of the interdecadal Pacific oscillation (IPO) on climate and drought cycles in the Great Basin-a process that is inferred from the historical record of the GSL level variations. This modulation involves a phase lag of 6-9 yr, a result of a distinctive teleconnection pattern that develops during the transition points between the IPO's warm and cool phases. Such a circumstance provides a plausible explanation for the delay in the occurrence of local droughts-pluvials over the Great Basin to the IPO cycle-a phenomenon suggested by the spectral coherence analysis. The CM2.1 simulation corroborates the processes involved in the events: a transition-phase teleconnection of the IPO does exist, and it affects climate anomalies in the Great Basin.

The possibility that drought cycles in the American West evolve in association with the IPO life cycle had been statistically researched by others, such as the spatiotemporal analysis by Zhang and Mann (2005). In addition, recent studies exploring long-range forecasts of streamflow in the Colorado River basin have also found

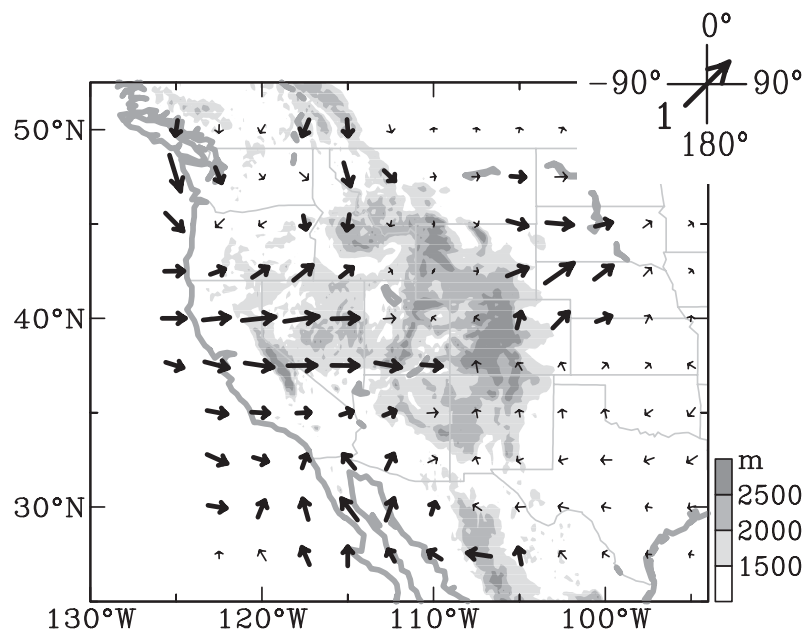

FIG. 9. As in Fig. 3a, but for the spectral coherence between the CM2.1 annual precipitation and Niño-3.4 index. 
significant lags from the tropical Pacific SST on the order of $3 \mathrm{yr}$ (e.g., Lamb et al. 2011). The present study is a further step toward recognizing the process connecting multidecadal drought variability to an explicit teleconnection pattern, which is atypical to that of the classic PNA mechanism. The teleconnection elucidated here, one that is excited during the IPO transitions, provides a plausible explanation for the existence of the phase lag. The seeming "memory" of such a phase lag lies in the ocean circulation (i.e., the IPO); the atmospheric circulations merely respond to the evolving anomalies of SST and diabatic heating (i.e., teleconnections). Awareness of the IPO life cycle and its commensurate dynamics initiated between the ocean and the atmosphere will serve to improve decadal prediction of climate for the American West.

Acknowledgments. We are grateful to Lucia Bunge for providing the long-term Niño-3.4 SST index, and to Andrew Wittenberg for making the CM2.1 model simulation available to us. Insightful discussion with Upmanu Lall in a companion study as well as valuable comments from Michael Alexander and two anonymous reviewers are highly appreciated. The MTM statistical package was obtained from Michael Mann's website: http://www.meteo. psu.edu/ $\sim$ mann/Mann/tools/tools.html. This study was supported by the USDA-CSREES Drought Management, Utah Project, and approved by the Utah Agricultural Experiment Station, Utah State University as journal paper 8233 . Support for the $20 \mathrm{CR}$ is provided by the U.S. Department of Energy, Office of Science Innovative and Novel Computational Impact on Theory and Experiment (DOE INCITE) program, and Office of Biological and Environmental Research (BER), and by the NOAA Climate Program Office.

\section{REFERENCES}

Allan, R., 2000: ENSO and climatic variability in the last 150 years. El Niño and the Southern Oscillation: Multiscale Variability, Global and Regional Impacts, H. F. Diaz and V. Markgrav, Eds., Cambridge University Press, 3-56.

Branstator, G., 1983: Horizontal energy propagation in a barotropic atmosphere with meridional and zonal structure. J. Atmos. Sci., 40, 1689-1708.

Bunge, L., and A. J. Clarke, 2009: A verified estimation of the El Niño index Niño-3.4 since 1877. J. Climate, 22, 3979-3992.

Cayan, D. R., M. D. Dettinger, H. F. Diaz, and N. E. Graham, 1998: Decadal variability of precipitation over western North America. J. Climate, 11, 3148-3166.

Compo, G. P., and Coauthors, 2011: The Twentieth Century Reanalysis Project. Quart. J. Roy. Meteor. Soc., 137, 1-28.

Cook, E. R., and P. J. Krusic, 2004: North American summer PDSI reconstructions. IGBP PAGES/World Data Center for Paleoclimatology Data Contribution Series 2004-045, NOAA/NGDC Paleoclimatology Program, Boulder, CO, 24 pp.
- R. Seager, M. A. Cane, and D. W. Stahle, 2007: North American drought: Reconstructions, causes, and consequences. Earth Sci. Rev., 81, 93-134.

— R. D. D'Arrigo, and K. J. Anchukaitis, 2008: ENSO reconstructions from long tree-ring chronologies: Unifying the differences? Proc. Workshop on Reconciling ENSO Chronologies for the Past 500 Years, Moorea, French Polynesia, Meteo-France.

Delworth, T. L., and Coauthors, 2006: GFDL's CM2 Global Coupled Climate Models. Part I: Formulation and simulation characteristics. J. Climate, 19, 643-674.

DeWeaver, E., and S. Nigam, 2004: On the forcing of ENSO teleconnections by anomalous heating and cooling. J. Climate, 17, 3225-3235.

Folland, C. K., J. A. Renwick, M. J. Salinger, and A. B. Mullan, 2002: Relative influences of the Interdecadal Pacific Oscillation and ENSO on the South Pacific Convergence Zone. Geophys. Res. Lett., 29, 1643, doi:10.1029/2001GL014201.

Gershunov, A., and T. P. Barnett, 1998: Interdecadal modulation of ENSO teleconnections. Bull. Amer. Meteor. Soc., 79, 2715-2725.

Gillies, R. R., O.-Y. Chung, S.-Y. Wang, and P. Kokoszka, 2011: Incorporation of Pacific SSTs in a time series model towards a longer-term forecast for the Great Salt Lake elevation. J. Hydrometeor., 12, 474-480.

Gray, S. T., J. L. Betancourt, C. L. Fastie, and S. T. Jackson, 2003: Patterns and sources of multidecadal oscillations in droughtsensitive tree-ring records from the central and southern Rocky Mountains. Geophys. Res. Lett., 30, 1316, doi:10.1029/ 2002 GL016154.

Herweijer, C., R. Seager, E. R. Cook, and J. Emile-Geay, 2007: North American droughts of the last millennium from a gridded network of tree-ring data. J. Climate, 20, 1353-1376.

Horel, J. D., and J. M. Wallace, 1981: Planetary-scale atmospheric phenomena associated with the Southern Oscillation. Mon. Wea. Rev., 109, 813-829.

Iacobucci, A., and A. Noullez, 2005: A frequency selective filter for short-length time series. Comput. Econ., 25, 75-102.

Jiang, X., and N.-C. Lau, 2008: Intraseasonal teleconnection between North American and western North Pacific monsoons with 20-day time scale. J. Climate, 21, 2664-2679.

Lall, U., and M. E. Mann, 1995: The Great Salt Lake: A barometer of low-frequency climatic variability. Water Resour. Res., 31, 2503-2515.

Lamb, K. W., T. C. Piechota, O. A. Aziz, and G. A. Tootle, 2011: A basis for extending long-term streamflow forecasts in the Colorado River Basin. J. Hydrol. Eng., 1000, doi:10.1061/ (ASCE)HE.1943-5584.0000153.

Livezey, R. E., and W. Y. Chen, 1983: Statistical field significance and its determination by Monte Carlo techniques. Mon. Wea. Rev., 111, 46-59.

Mann, M. E., 2004: On smoothing potentially non-stationary climate time series. Geophys. Res. Lett., 31, L07214, doi:10.1029/ 2004 GL019569.

_ global surface temperatures. Geophys. Res. Lett., 20, 1055-1058.

— seasonal cycle of temperature: Model versus observations. Geophys. Res. Lett., 23, 1111-1114.

_, U. Lall, and B. Saltzman, 1995: Decadal-to-centennial-scale climate variability: Insights into the rise and fall of the Great Salt Lake. Geophys. Res. Lett., 22, 937-940.

Mantua, N. J., S. R. Hare, Y. Zhang, J. M. Wallace, and R. C. Francis, 1997: A Pacific interdecadal climate oscillation with impacts 
on salmon production. Bull. Amer. Meteor. Soc., 78, 10691079.

Moon, Y.-I., and U. Lall, 1996: Atmospheric flow indices and interannual Great Salt Lake variability. J. Hydrol. Eng., 1, 55-62.

Pierce, D. W., T. P. Barnett, B. D. Santer, and P. J. Gleckler, 2009: Selecting global climate models for regional climate change studies. Proc. Natl. Acad. Sci. USA, 106, 8441-8446.

Plumb, R. A., 1985: On the three-dimensional propagation of stationary waves. J. Atmos. Sci., 42, 217-229.

Reichler, T., and J. Kim, 2008: How well do coupled models simulate today's climate? Bull. Amer. Meteor. Soc., 89, 303-311.

Santer, B. D., and Coauthors, 2009: Incorporating model quality information in climate change detection and attribution studies. Proc. Natl. Acad. Sci. USA, 106, 14 778-14 783.

Schubert, S. D., M. J. Suarez, P. J. Pegion, R. D. Koster, and J. T. Bacmeister, 2004: On the cause of the 1930s Dust Bowl. Science, 303, 1855-1859.

_ , and Coauthors, 2009: A U.S. CLIVAR project to assess and compare the responses of global climate models to droughtrelated SST forcing patterns: Overview and results. J. Climate, 22, 5251-5272.

Seager, R., Y. Kushnir, C. Herweijer, N. Naik, and J. Velez, 2005: Modeling of tropical forcing of persistent droughts and pluvials over western North America: 1856-2000. J. Climate, 18, 4065-4088.

Smith, T. M., R. W. Reynolds, T. C. Peterson, and J. Lawrimore, 2008: Improvements to NOAA's historical merged land-ocean surface temperature analysis (1880-2006). J. Climate, 21, 2283 2296.

Takaya, K., and H. Nakamura, 2001: A formulation of a phaseindependent wave-activity flux for stationary and migratory quasigeostrophic eddies on a zonally varying basic flow. J. Atmos. Sci., 58, 608-627.

UDNR, 2007: Drought in Utah: Learning from the past-Preparing for the future. Utah State Water Plan, $145 \mathrm{pp}$. [Available online at http://www.water.utah.gov/DroughtReport/Drought2008A.pdf.]

van Oldenborgh, G. J., S. Y. Philip, and M. Collins, 2005: El Niño in a changing climate: A multi-model study. Ocean Sci., 1, 81-95.

Wang, S.-Y., R. R. Gillies, J. Jin, and L. E. Hipps, 2010: Coherence between the Great Salt Lake level and the Pacific quasidecadal oscillation. J. Climate, 23, 2161-2177.

, - — , L. E. Hipps, and J. Jin, 2011: A transition-phase teleconnection of the Pacific quasi-decadal oscillation. Climate Dyn., 36, 681-693.

Wittenberg, A. T., 2009: Are historical records sufficient to constrain ENSO simulations? Geophys. Res. Lett., 36, L12702, doi:10.1029/2009GL038710.

_- A. Rosati, N.-C. Lau, and J. J. Ploshay, 2006: GFDL's CM2 global coupled climate models. Part III: Tropical Pacific climate and ENSO. J. Climate, 19, 698-722.

Zhang, R., and T. L. Delworth, 2007: Impact of the Atlantic Multidecadal Oscillation on North Pacific climate variability. Geophys. Res. Lett., 34, L23708, doi:10.1029/2007GL031601.

Zhang, R.-H., and S. Levitus, 1997: Structure and cycle of decadal variability of upper-ocean temperature in the North Pacific. J. Climate, 10, 710-727.

Zhang, Y., J. M. Wallace, and D. S. Battisti, 1997: ENSO-like interdecadal variability: 1900-93. J. Climate, 10, 1004-1020.

Zhang, Z., and M. E. Mann, 2005: Coupled patterns of spatiotemporal variability in Northern Hemisphere sea level pressure and conterminous U.S. drought. J. Geophys. Res., 110, D03108, doi:10.1029/2004JD004896. 